\title{
Metabolism of alcohol (ethanol) in man
}

\section{By G. L. S. Pawan, Metabolic Division, Department of Medicine, The Middlesex Hospital Medical School, London $W_{\mathrm{I}} P{ }_{7} P N$}

It is well recognized that the primary alcohol, ethanol, can be absorbed unchanged along the whole length of the digestive tract, that absorption takes place rapidly from the stomach (about $20 \%$ ), and most rapidly from the small gut (about $80 \%$ ). The rate of absorption after drinking is affected by several factors, for example the volume, concentration (10-20\% solutions are most rapidly absorbed) and nature of the alcoholic drink, the presence or absence of food in the stomach, rate of gastric emptying, pylorospasm, permeability of the gastric and intestinal tissues, individual variations. After absorption into the blood-stream, alcohol is distributed quickly throughout the total body water (Berggren \& Goldberg, 1940; Harger \& Hulpieu, 1956; Pappenheimer \& Heisey, 1963) and is subsequently metabolized at a steady rate. A method which makes use of this property of ethanol has been successfully employed for measuring the total body water volume in human subjects (Pawan \& Hoult, 1963; Pawan, I965). After equilibration, normally $\mathrm{I}-\mathrm{I} \cdot 5 \mathrm{~h}$ after drinking, the alcohol concentration in any body fluid depends on the water content of that fluid (Pawan, I967, I970; Pawan \& Grice, I968). Over 90\% of the absorbed alcohol is metabolized in the body, yielding some $7 \mathrm{kcal} / \mathrm{g}$ on complete oxidation to carbon dioxide and water, with a concomitant fall in the respiratory quotient; the remainder is excreted unchanged in the urine, expired air and sweat.

The main site of metabolism of ethanol is the liver, although some other tissues, for example kidney, muscle, lung, intestine and possibly even the brain, may metabolize smaller quantities. Fig. I shows the main pathways of ethanol metabolism. It is generally believed that the rate-limiting step in the metabolism of alcohol is its conversion to acetaldehyde, a reaction catalysed by the zinc-containing enzyme, alcohol dehydrogenase (ADH). This process occurs chiefly in the soluble cytoplasm of liver cells, with nicotinamide adenine dinucleotide (NAD) acting as the hydrogen acceptor. However, particularly in alcoholics, some ethanol may be oxidized by the peroxidase-xanthine oxidase-catalase system, and possibly other oxidases both in liver and plasma (Trémolières \& Carré, 1960, 196r). Small amounts of alcohol may also be converted to ethyl glucuronide (Kamil, Smith \& Williams, I952), ethyl sulphate and other esters, and excreted in the urine. Orme-Johnson \& Ziegler ( 1965$)$ have described a 'mixed-function enzyme', and Lieber and his colleagues (Lieber \& DeCarli, I968a,b, I969; Rubin, Hutterer \& Lieber, 1968; Baraona \& Lieber, 1970; Rubin, Bacchin, Gang \& Lieber, 1970) have found liver microsomes, which comprise the smooth endoplasmic reticulum (SER), capable of oxidizing 


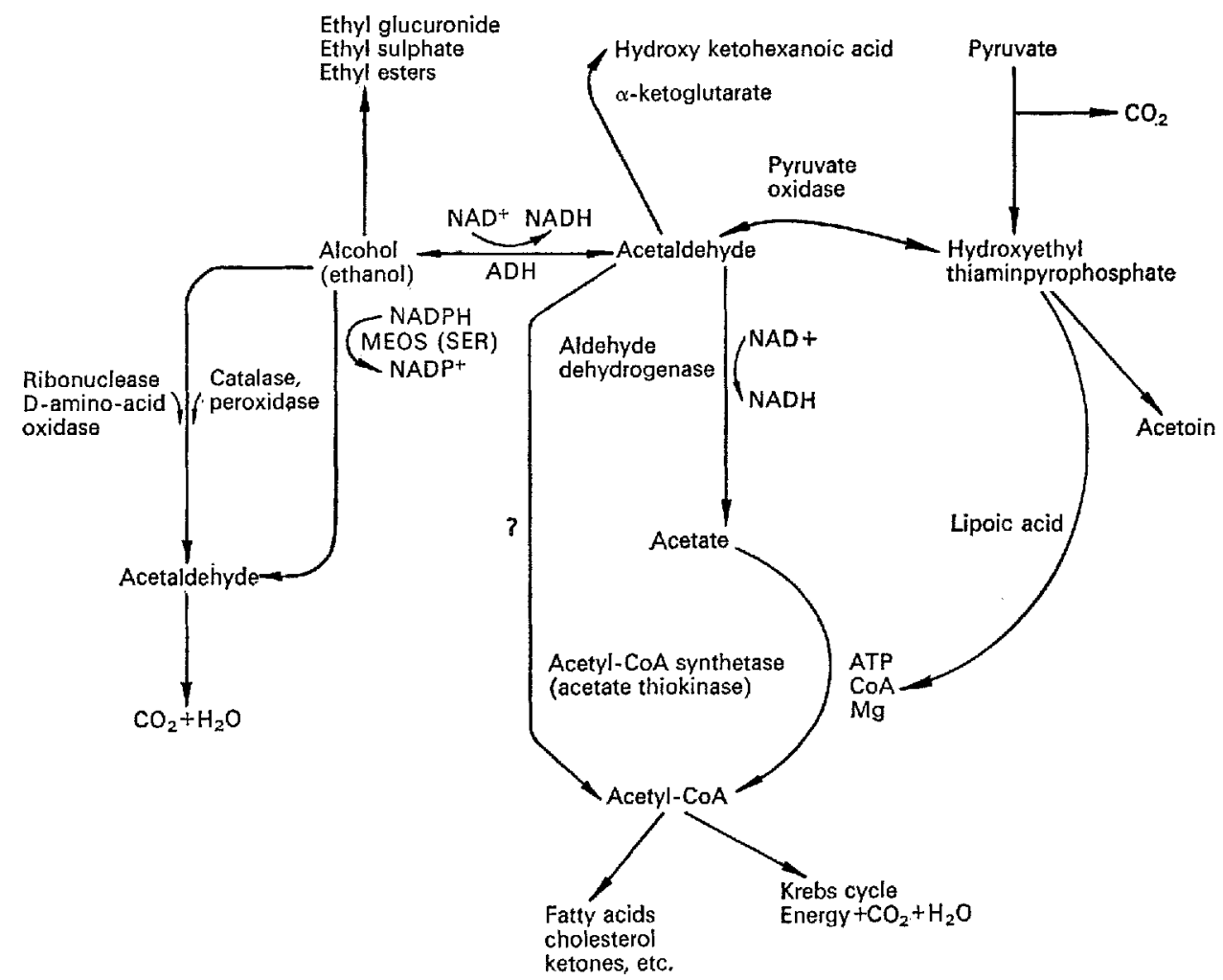

Fig. 1. Pathways of alcohol (ethanol) metabolism in man. ADM, alcohol dehydrogenase; MEOS, microsomal ethanol oxidizing system; SER, smooth endoplasmic reticulum.

ethanol, using $\mathrm{NADPH}$ (instead of $\mathrm{NAD}^{+}$) at a $\mathrm{pH}$ optimum of $7^{\circ} \circ$. They have also shown that chronic ethanol administration produced proliferation of the SER and induction of the microsomal ethanol oxidizing system (MEOS) leading to increased blood ethanol clearance. However, the significance in man of the MEOS has been questioned by several authors (Klaasen, I969; Tephly, Tinelli \& Watkins, r969; Isselbacher \& Carter, I970; Kalant, Khanna \& Marsham, 1970; Khanna \& Kalant, I970; and Khanna, Kalant, Lin \& Bustos, I97 I). It has also been suggested that androgenic steroids can induce kidney $\mathrm{ADH}$ and explain the increased alcohol metabolism seen in adult males compared with females (Ohno, Stenius, Christian, Harris \& Ivey, 1970).

The acetaldehyde formed in the first oxidative step in the metabolism of ethanol is converted to acetate, a reaction catalysed by aldehyde dehydrogenase, utilizing $\mathrm{NAD}$ as cofactor, and eventually to acetyl-CoA, the Krebs cycle, and other reactions (Fig. I). Acetaldehyde can also be converted to other substances, such as acetoin (Stotz, Westerfeld \& Berg, 1944) and hydroxyketohexanoic acid (Westerfeld \& Bloom, ig69).

The availability of unreduced NAD in the cell sap seems to be important in alcohol metabolism, since NADH competes with NAD for binding sites on $\mathrm{ADH}$ and, in 
sufficient concentration, may inhibit the rate of ethanol dehydration (Mahler, Baker \& Shiner, I962). The NADH formed in the oxidative steps must be continually reoxidized to NAD for alcohol oxidation to proceed. In the cytoplasm of liver cells the reoxidation of $\mathrm{NADH}$ may be coupled with the reduction of pyruvate to lactate (Westerfeld, Stotz \& Berg, I943; Lundquist, Fugmann, Kläning \& Rasmussen, I959), and to the reductive synthesis (Lieber \& Schmid, I96I), elongation and saturation of fatty acids; but perhaps the most important route for reoxidation of the $\mathrm{NADH}$ involves the mitochondrial flavoprotein-cytochrome electron transfer system coupled with oxidative phosphorylation (Lehninger, 1953-54; Green \& Crane, I958; Lardy, Lee \& 'Takemori, I960). 'The 'carrier' of the hydrogen equivalents from NADH across the relatively impermeable mitochondrial membranes for oxidation in the intra-mitochondrial compartment may be substances like malate and glutamate (Chappell, I 968), $\alpha$-glycerophosphate (Lardy et al. 1960), $\beta$-hydroxybutyrate (Devlin \& Bedell, 1959, 1960).

\section{Factors influencing rate of metabolism}

In theory, the B vitamins, nicotinamide and riboflavin, participate in the metabolism of alcohol, for they are implicated in the formation of NAD and flavinadenine dinucleotide (FAD) respectively. It is also possible that ascorbic acid (vitamin C) and the tocopherols (vitamin E), which may be involved in oxidationreduction reactions, affect alcohol oxidation, and it has also been reported that pyridoxine (vitamin $B_{6}$ ) increases the rate of alcohol metabolism in man (Wordsworth, I953). Sugars, which yield pyruvate and participate in fatty acid synthesis, may also facilitate ethanol oxidation by means of NADH reoxidation pathways. There have been many claims that administration of vitamins and sugars can increase the rate of 'sobering up' in man and laboratory animals, but the published results are equivocal (Lieber, I967). Caffeine and strong black coffee, dietary factors, physical exercise, environmental temperature changes, thyroid hormones, oxygen therapy and various drugs - for example oral antidiabetic agents (Larsen \& Madsen, I962) have all been suggested from time to time as being capable of affecting the rate of alcohol metabolism in man. The author therefore decided some years ago to reinvestigate the effects of various factors which may affect the rate of metabolism of standard oral doses of alcohol under controlled conditions in a large number of human volunteers. All the experimental subjects were occasional moderate drinkers.

\section{Experimental procedure (After Pawan, 1967, 1968a,b)}

In the morning after an overnight fast, each subject was given an oral dose of ethanol ( $0.5 \mathrm{~g} / \mathrm{kg}$ body-weight) as a $10-20 \%$ aqueous solution. One hour after the ethanol was taken and at $30 \mathrm{~min}$ intervals thereafter for the following $4 \mathrm{~h}$, venous blood samples were obtained for analysis of their ethanol and water contents. The ethanol values in the blood-water of the samples were plotted against time, and the slope of the rectilinear alcohol curve taken as an index of the rate of metabolism of alcohol. The experiments were repeated in each subject at intervals of $3^{-5} \mathrm{~d}$, and 
only those subjects who exhibited reproducible alcohol curves were used in subsequent experiments. Each person served as his own control. Having established the slope of the alcohol curve with the standard dose of alcohol in each subject, experiments were repeated in the same way, but the effects of the following procedures studied.

Physical exercise. Fairly intensive physical exercise, consisting of a $4.8 \mathrm{~km}(3$ miles) run or a $910 \mathrm{~m}$ (1000 yd) swim, was performed in a period of $20 \mathrm{~min}$, commencing at $60 \mathrm{~min}$ and ending at $80 \mathrm{~min}$ after the dose of alcohol was administered. Despite the increased pulmonary ventilation, sweat loss and general rise in metabolic rate, this level of physical exercise did not significantly affect the rate of alcohol metabolism (Pawan, r968a).

Vitamin supplements. The subjects were given vitamin supplements at the following concentrations daily for $10 \mathrm{~d}$ : thiamin hydrochloride $10 \mathrm{mg}$, riboflavin $4 \mathrm{mg}$, nicotinamide $40 \mathrm{mg}$, pyridoxine hydrochloride $4 \mathrm{mg}$, ascorbic acid $200 \mathrm{mg}$, retinol 5000 i.u., calciferol $2 \mathrm{mg}$, mixed tocopherols $20 \mathrm{mg}$. On the 5 th and roth days of vitamin supplementation the ethanol experiments were repeated, the daily dose of vitamins being taken together with the ethanol. The vitamins produced no effect on the rate of ethanol metabolism. On repeating the experiments $5 \mathrm{~d}$ later, and giving each subject much larger doses of vitamins (ascorbic acid $600 \mathrm{mg}$, nicotinamide I $50 \mathrm{mg}$, pyridoxine $20 \mathrm{mg}$ ) together with the dose of alcohol, no significant effect on the rate of alcohol metabolism was obtained (Pawan, I968b). It was concluded that in these normal, well-nourished individuals, vitamin supplementation did not affect the rate of alcohol metabolism.

Effect of sugars. In similar experiments $30 \mathrm{~g}$ doses of sugars (glucose, fructose, galactose and sucrose, each sugar given on different days) were taken with the alcohol at intervals of $3-5 \mathrm{~d}$. Glucose and galactose were without effect, but fructose produced a significant increase in the rate of alcohol metabolism (Pawan, 1968b) (Fig. 2). On other occasions, when the sugar was administered 30 min after the alcohol was taken (each sugar on different days), it was found that glucose was again ineffective but fructose increased the rate of alcohol metabolism by $15-30 \%$. When the experiment was repeated, but with a $60 \mathrm{~g}$ dose of sucrose, a greater effect on the rate of metabolism was seen (Pawan, $1968 b$ ), but this was still less than that produced by $3^{\circ} \mathrm{g}$ fructose alone. This latter effect is difficult to explain, but may be related to rate of gut digestion of sucrose or to substrate effects on the liver. The fructose effect on ethanol metabolism is not completely understood, but it has been suggested (Tygstrup, Winkler \& Lundquist, 1965; Thieden \& Lundquist, 1967) that glyceraldehyde, a fructose metabolite, is reduced to glycerol by $\mathrm{ADH}$, thereby converting the ADH-NADH binary complex to $\mathrm{ADH}-\mathrm{NAD}$ more quickly than would be possible by the unmediated dissociation of ADH-NADH followed by reassociation of the enzyme with NAD. Another possibility is that some fructose is reduced to sorbitol, thereby increasing the supply of NAD. Both these effects would alter the redox of the liver cell towards the oxidized state, thus improving intracellular conditions and favouring increased ethanol oxidation. 


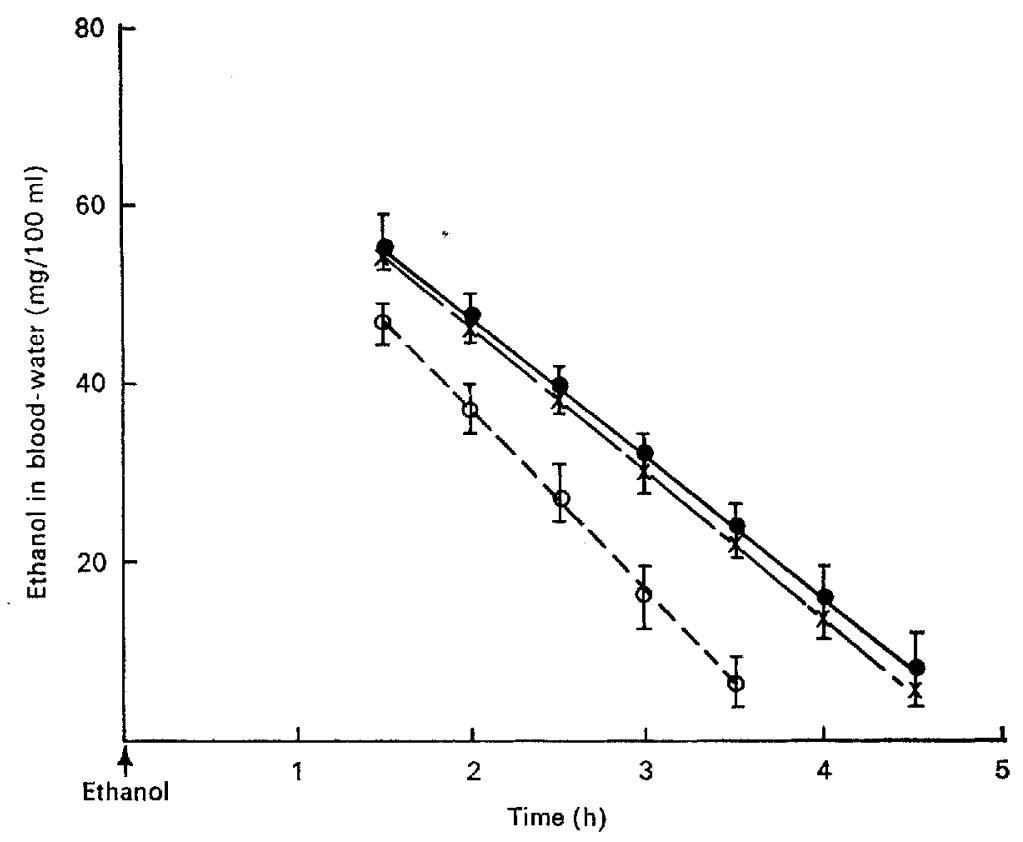

Fig. 2. Plasma alcohol concentrations (-O) of twelve men given $0.5 \mathrm{~g}$ ethanol $/ \mathrm{kg}$ body-weight on three occasions, and the effect of $30 \mathrm{~g}$ glucose $(x-\infty)$ and of $30 \mathrm{~g}$ fructose $(\mathrm{O}--\mathrm{O})$ taken with this dose of alcohol in the same subjects. The vertical bars represent the standard errors of the mean.

Thyroid hormones. The effect of administering tri-iodothyronine $(75 \mu \mathrm{g} / \mathrm{d}$, or $15 \circ$ $\mu \mathrm{g} / \mathrm{d}$ ) for a 7 -d period was investigated with the same experimental procedures. At these dosages this hormone did not significantly affect the rate of metabolism of alcohol in our subjects.

Caffeine and strong black coffee. Caffeine (50 $\mathrm{mg})$ and two cups of strong, unsweetened black coffee were given I $h$ after the dose of alcohol; no effect on the rate of alcohol metabolism was seen (Pawan, I967a).

Effect of nature of the antecedent diet. The effects of gross alterations of diet on the rate of metabolism of alcohol were studied. The subjects were given one of each of the following diets (after Kekwick \& Pawan, I957), for a 5-7 d period: (I) a control normally proportioned diet of $2200 \mathrm{kcal} / \mathrm{d}$; (2) $1000 \mathrm{kcal} / \mathrm{d}$ of normal proportions; (3) $1000 \mathrm{kcal} / \mathrm{d}$ containing $90 \%$ of energy as fat; (4) $1000 \mathrm{kcal} / \mathrm{d}$ containing $90 \%$ of energy as protein.

The sequence in which the diets were given varied in some of the subjects. In all of the subjects the rate of metabolism of the standard dose of alcohol was studied in the morning after an overnight fast, on the first and last day of each dietary period. Each subject acted as his own control. No significant effect on the rate of alcohol metabolism was seen after any of the dietary regimens, except the high-fat diet (3) when the subjects, after they had been on this diet for about one week, showed a decreased ability to metabolize alcohol (Pawan, I968c). The explanation of this 
may possibly be a relative depletion of the necessary enzymes or cofactors, an enhancement of the reduced redox state of liver cells, or probably to inhibition of the enzymes, ADH and aldehyde dehydrogenase by free fatty acids (Rawat, 1969) which are considerably increased in concentration by this type of diet.

Starvation. In obese subjects who were being starved for therapeutic reasons (receiving water and adequate vitamin supplements only) the alcohol experiments were carried out before and at the end of the $7-\mathrm{d}$ starvation period. This period of starvation decreased the rate of alcohol metabolism by about 22\% (Pawan, I968c). The effect of starvation on alcohol metabolism may be similarly explained as the effect of the high-fat diet described above.

In the author's experience, the only procedures which significantly alter the rate of alcohol metabolism in man are fructose administration which speeds up the process, and starvation and high-fat diets which decrease it. Various other drugs may have some effect but they require further evaluation. In addition some effects are produced on cerebral function without affecting blood-alcohol concentrations. Perhaps, for rapid elimination of alcohol from the blood-stream in special cases, haemodialysis using the artificial kidney may, if available, be of great value (Wieth \& Jørgensen, I96r; Perey, Helle \& MacLean, 1965).

Recent clinical studies have confirmed the value of fructose in speeding up the rate of ethanol metabolism and 'sobering up' intoxicated persons (Patel, Paton, Rowan, Lawson \& Linton, I969; Lowenstein, Simone, Boulter \& Nathan, 1970). Blomstrand (1970) has also shown in human subjects that 4-methyl-pyrazole significantly reduces the rate of alcohol metabolism via its inhibition of $\mathrm{ADH}$.

Other interesting metabolic effects of cthanol include its ability to depress secretion of the posterior pituitary antidiuretic hormone, stimulation of gastric secretion, reduction in neoglucogenesis from some precursors, stimulation of adrenocortical activity (Jenkins \& Connolly, 1968), raising of plasma growth hormone levels (Bellet, Yoshimine, De Castro, Roman, Parmar \& Sandberg, 1971), and alterations in plasma and liver lipid levels.

\section{REFERENCES}

Baraona, E. \& Lieber, C. S. (1970). F. clin. Invest. 49, 769.

Bellet, S., Yoshimine, N., De Castro, O. A. P., Roman, L., Parmar, S. S. \& Sandberg, H. (197I). Metabolism 20, 762 .

Berggren, S. M. \& Goldberg, L. (1940). Acta physiol, scand. I, 246.

Blomstrand, R. (1970). Ind. Med. Surg. 39, 311.

Chappell, J. B. (1968). Br. med. Bull. 24, 150.

Devlin, T. M. \& Bedell, B. H. (1959). Biochim. biophys. Acta 36, 564.

Devlin, T. M. \& Bedell, B. H. (I960). F. biol. Chem. 235, 2134.

Green, D. E. \& Crane, F. L. (1958). Proc. int. Symp. Enzyme Chemistry p. 275 [B. Chance, editor]. Tokyo: Waruzen Co.

Harger, R. N. \& Hulpieu, H. R. (1956). In Alcoholism p. Io3 [G. N. Thompson, editor]. Springfield, Ill.: Charles C. Thomas.

Isselbacher, K. J. \& Carter, E. A. (1970). Biochem. biophys. Res. Commun. 39, 530.

Jenkins, J. S. \& Connolly, J. (1968). Br, med. F. ii, 804.

Kalant, H., Khanna, J. M. \& Marsham, J. (I970). F. Pharmac. exp. Ther. 175, 318.

Kamil, I. A., Smith, J. N. \& Williams, R. 'T. (I 952). Biochem. J. 5r, xxxii.

Kekwick, A. \& Pawan, G. L. S. (1957). Metabolism 6, 447.

Khanna, J. M. \& Kalant, H. (1970). Biachem. Pharmac. 19, 2033. 
Khanna, J. M., Kalant, H., Lin, G. \& Bustos, G. O. (I971). Biochem. Pharmac. 20, 3269.

Klaasen, C. D. (1969). Proc. Soc. exp. Biol. Med. 132, 1099.

Lardy, H. A., Lee, Y. P. \& Takemori, A. E. (1960). Ann. N.Y. Acad. Sci. 86, 506.

Larsen, J. \& Madsen, J. (1962). Proc. Soc. exp. Biol. Med. rog, r2o.

Lehninger, A. L. (1953-54). Harvey Lect. 49, 176.

Lieber, C. S. (1967). A. Rev. Med. 18, 35.

Lieber, C. S. \& DeCarli, L. M. (1968a) Science, N.Y. 162, 917.

Liebcr, C. S. \& DeCarli, L. M. (1968b). F. clin. Invest. 47, 629.

Lieber, C. S. \& DeCarli, L. M. (1969). Clin. Res, 17, 306.

Lieber, C. S. \& Schmid, R. (196r). F. clin. Invest. 40, 394.

Lowenstein, L. M., Simone, R., Boulter, P. \& Nathan, P. (1970). F. Am. med. Ass. 213, I899.

Lundquist, F., Fugmann, U., Kläning, E. \& Rasmussen, H. (1959). Biochem. f. 72, 409.

Mahler, H. R., Baker, R. H. Jr \& Shiner, V. J. Jr (1962). Biochemistry, N.Y. 1, 47.

Ohno, S., Stenius, C., Christian, L., Harris, C. \& Ivey, C. (1970). Biochem. Genetics 4, $\mathbf{5}^{6} \mathbf{5}$.

Orme-Johnson, W. H. \& Ziegler, D. M. (1965). Biochem. biophys. Res. Commun. 21, 78.

Pappenheimer, J. R. \& Heisey, S. R. (1963). In Drugs and Membranes p. 95 [C. A. M. Hogben and P. Lindgren, editors]. Oxford: Pergamon Press.

Patel, A. R., Paton, A. M., Rowan, T., Lawson, D. H. \& Linton, A. L. (1969). Scott. med. F. x4, 268.

Pawan, G. L. S. (1965). Br. J. Radiol. 38, 557.

Pawan, G. L. S. (1967). Biochem. f. ro6, I9P.

Pawan, G. L. S. (1968a). Nature, Lond. 218, 966.

Pawan, G. L. S. (I g68b). Nature, Lond. 220, 374.

Pawan, G. L. S. (1968c). Proc. Nutr. Soc. 27, 58 A.

Pawan, G. L. S. (I970). Nutrition, Lond. 24, 77.

Pawan, G. L. S. \& Grice, K. (1968). Lancet ii, 1o16.

Pawan, G. L. S. \& Hoult, W. H. (1963). Biochem. F. 87, 6P.

Perey, B. J., Helle, S. J. \& MacLean, L. D. (1965). Can. F. Surg. 8, 194.

Rawat, A. K. (1969). Eur. F. Biochem. 9, 93.

Rubin, E., Bacchin, P., Gang, H. \& Lieber, C. S. (1970). Lab. Invest. 22, 569.

Rubin, E., Hutterer, F. \& Lieber, C. S. (1968). Science, N,Y. 159, 1469.

Stotz, E., Westerfeld, W. W. \& Berg, R. L. (I944). F. biol. Chem. r52, 4 1.

Tephly, 'T. R., Tinelli, F. \& Watkins, W. D. (1969). Science, N.Y. 166, 627.

Thieden, H. I. D. \& I undquist, F. (I g67). Biochem. F. 102, I77.

Trémolières, J. \& Carré, L. (1960). C. r. hebd. Séanc. Acad. Sci., Paris, 251, 2785.

Trémolières, J. \& Carré, L. (1961). C. r. Séanc. Soc. Biol. I55, 1022.

Tygstrup, N., Winkler, K. \& Lundquist, F. (1965). F. clin. Invest. 44, 8I7.

Westerfeld, W. W. \& Bloom, R. J. (г969). Archos Biol. Med. exp. Organo de la Sociedad de Biología de Chile, Suppl. no. 3 , p. 26.

Westerfeld, W. W., Stotz, E. \& Berg, R. L. (1943). \%. biol. Chem. 149, 237.

Wieth, J. O. \& Jørgensen, H. E. (196r). Dan. med. Bull. 8, 103.

Wordsworth, V. P. (1953). Br. med. F. i, 935. 